\title{
A genomewide survey on basic helix-loop-helix transcription factors in rat and mouse
}

\author{
Xiaodong Zheng $\cdot$ Yong Wang $\cdot$ Qin Yao •
}

Zhe Yang $\cdot$ Keping Chen

Published online: 2 July 2009

(C) Springer Science+Business Media, LLC 2009

Erratum to: Mamm Genome (2009) 20(4):236-246

DOI 10.1007/s00335-009-9176-7

In the April 2009 issue of Mammalian Genome (volume 20, number 4, pp. 236-246), the authors' full names were shortened to initials and surnames only. We regret this error.

$\mathrm{X}$. Zheng and Y. Wang are jointly first authors.

The online version of the original article can be found under doi:10.1007/s00335-009-9176-7.

X. Zheng · Q. Yao $\cdot$ Z. Yang $\cdot$ K. Chen $(\bowtie)$ Institute of Life Sciences, Jiangsu University, 301 Xuefu Road, Zhenjiang 212013, People's Republic of China e-mail: kpchen@ujs.edu.cn

Y. Wang

School of Food and Biological Engineering, Jiangsu University, 301 Xuefu Road, Zhenjiang 212013, People's Republic of China 